\title{
Toxicidade de compostos sintéticos e naturais sobre Tetranychus urticae e o predador Phytoseiulus macropilis
}

\author{
Bruce Veronez ${ }^{(1)}$, Mário Eidi Sato(1) e Roberto Lomba Nicastro(2)
}

(1)Instituto Biológico, Centro Experimental Central, Laboratório de Acarologia, Rodovia Heitor Penteado, Km 3, CEP $13094-430$ Campinas, SP. E-mail: bruce_veronez@yahoo.com.br, mesato@biologico.sp.gov.br ${ }^{(2)}$ Universidade de São Paulo, Centro de Energia Nuclear na Agricultura, Laboratório de Radiobiologia e Ambiente, Avenida Centenário, no 303, CEP 13400-970 Piracicaba, SP. E-mail: Iombanicastro@yahoo.com.br

\begin{abstract}
Resumo - O objetivo deste trabalho foi avaliar a toxicidade de compostos sintéticos e naturais sobre Tetranychus urticae e o predador Phytoseiulus macropilis. A mortalidade e a taxa de crescimento de T. urticae e seu predador foram avaliadas após a aplicação de: abamectina, clofentezina, fenpropatrina, fenpiroximato, propargito, enxofre e espiromesifeno, nas concentrações recomendadas; óleos de nim (Natuneem e Sempre Verde Killer Neem a 1\%); e extratos aquosos a 10\% de Dieffenbachia brasiliensis, Annona squamosa, Ruta graveolens, Agave angustifolia, Melia azedarach, Sonchus oleraceus, Mentha spicata x M. suaveolens, Allium cepa, Laurus nobilis e Eucalyptus saligna. A toxicidade aguda e a influência dos compostos sobre a taxa de crescimento instantâneo dos ácaros foram avaliadas em laboratório. Extratos de A. cepa, A. angustifolia, produtos à base de óleo de nim, espiromesifeno, propargito, fenpiroximato, abamectina e fenpropatrina causaram mortalidade superior a $83 \% \mathrm{em}$ T. urticae. Extrato de A. angustifolia, Natuneem e clofentezina não causaram mortalidade significativa em P. macropilis. Agave angustifolia e Natuneem não afetaram significativamente a taxa de crescimento deste predador. Propargito, fenpiroximato, abamectina, fenpropatrina, espiromesifeno e extrato de L. nobilis afetaram severamente a população de P. macropilis.
\end{abstract}

Termos para indexação: acaricida, ácaro predador, ácaro-rajado, extrato de planta.

\section{Toxicity of synthetic and natural compounds on Tetranychus urticae and the predator Phytoseiulus macropilis}

\begin{abstract}
The objective of this work was to evaluate the toxicity of synthetic and natural compounds on Tetranychus urticae and the predator Phytoseiulus macropilis. Mortality and growth rates of T. urticae and its predator were evaluated after applications of: abamectin, clofentezine, fenpropathrin, fenpyroximate, propargite, sulfur and spiromesifen, at their recommended concentrations; neem oils (Natuneem and Sempre Verde Killer Neem at 1\%); and aqueous extracts at $10 \%$ of Dieffenbachia brasiliensis, Annona squamosa, Ruta graveolens, Agave angustifolia, Melia azedarach, Sonchus oleraceus, Mentha spicata x M. suaveolens, Allium cepa, Laurus nobilis, and Eucalyptus saligna. The acute toxicity and the influence of the compounds on the instantaneous growth rate of the mites were carried out in laboratory. Extracts of A. cepa, A. angustifolia, neem oil-based products, spiromesifen, propargite, fenpyroximate, abamectin and fenpropathrin caused mortality higher than $83 \%$ on T. urticae. Extract of $A$. angustifolia, Natuneem and clofentezine did not cause significant mortality rates on P. macropilis. Agave angustifolia and Natuneem did not affect significantly the growth rate of this predator. Propargite, fenpyroximate, abamectin, fenpropathrin, spiromesifen and extract of L. nobilis severely affected P. macropilis population.
\end{abstract}

Index terms: acaricide, predaceous mite, two-spotted spider mite, plant extract.

\section{Introdução}

O ácaro-rajado, Tetranychus urticae Koch (Acari: Tetranychidae), de distribuição cosmopolita, é uma praga importante em diversas culturas no Brasil como morangueiro, feijoeiro, pessegueiro, mamoeiro e ornamentais (Fadini et al., 2006). Em altas infestações, pode causar descoloração de folhas, perda da capacidade fotossintética e, eventualmente, morte de folhas e plantas (Devine et al., 2001). O controle químico tem sido a principal forma de controle do ácaro-rajado. Entre os problemas associados ao uso de acaricidas sintéticos estão o rápido desenvolvimento de resistência no ácaro-praga (Nicastro et al., 2010) e a elevada mortalidade de inimigos naturais, principalmente de ácaros da família Phytoseiidae (Silva et al., 2006).

Uma alternativa aos acaricidas sintéticos é o emprego de extratos de plantas e produtos derivados de nim, Azadirachta indica A. Juss. Nos programas de manejo integrado de pragas, o uso de extratos de plantas pode ser vantajoso em razão de suas propriedades repelentes, compatibilidade com inimigos naturais, curto efeito residual (Chiasson et al., 2004; Bernardi et al., 2010) e baixa toxicidade ao homem (Martinez, 2002; 
Venzon et al., 2008). Esses compostos se degradam mais rapidamente do que a maioria dos pesticidas químicos, o que implica em menor probabilidade de desenvolvimento de resistência em artrópodes-praga (Hincapié et al., 2008).

O uso de metabólitos secundários presentes em plantas vem sendo utilizado para o controle de pragas. Diversas substâncias oriundas de produtos intermediários ou finais do metabolismo secundário de plantas-como rotenoides, piretroides, alcaloides e terpenoides - podem interferir severamente no metabolismo de outros organismos e causar impactos variáveis, como repelência, deterrência alimentar e de oviposição, esterilização, bloqueio do metabolismo ou, interferência no desenvolvimento sem necessariamente causar a morte (Larcher, 2000).

Entre os inimigos naturais de ácaros fitófagos, os ácaros predadores da família Phytoseiidae são os mais importantes nas áreas agrícolas, com destaque para algumas espécies de Phytoseiulus (Evans), consideradas especialistas na predação deácaros do gênero Tetranychus (Dufour) (Moraes \& Flechtmann, 2008).

Phytoseiulus macropilis ocorre naturalmente em diversas regiões produtoras de morango no Brasil e apresenta grande eficiência predatória para o controle de ácaro-rajado (Garcia \& Chiavegato, 1997). O uso de ácaros predadores, como os da espécie $P$. macropilis, associado ao uso de produtos naturais seletivos pode ser uma alternativa viável para o controle do ácaro-rajado, minimizando os riscos de presença de resíduos de agrotóxicos nos alimentos e impactos ao ambiente.

Os extratos vegetais de Dieffenbachia brasiliensis, Annona squamosa, Ruta graveolens, Agave angustifolia, Melia azedarach, Sonchus oleraceus, Mentha spicata x M. suaveolens, Allium cepa, Laurus nobilis, selecionados no presente trabalho, mostraram-se promissores para o controle de T. urticae em condições de laboratório (Potenza et al., 1999a, 1999b; Vieira et al., 2006); entretanto, não foram encontrados relatos sobre o efeito desses compostos sobre o ácaro predador P. macropilis.

O objetivo deste trabalho foi avaliar a toxicidade de compostos sintéticos e naturais sobre $T$. urticae e seu predador $P$. macropilis.

\section{Material e Métodos}

Os experimentos foram realizados no Laboratório de Acarologia, do Instituto Biológico, em Campinas, SP, de março de 2009 a fevereiro de 2011. A população de T. urticae utilizada foi obtida em cultivo comercial de morangueiro, em Monte Alegre do Sul, SP, em 2009. Os ácaros foram mantidos em plantas de feijão-de-porco, Canavalia ensiformes, cultivadas em vasos, em câmaras climáticas (BOD) a $25 \pm 1^{\circ} \mathrm{C}$, com umidade relativa (UR) de $70 \pm 10 \%$ e fotófase de 14 horas (Sato et al., 2007).

$\mathrm{O}$ ácaro predador P. macropilis foi coletado em cultivo comercial de morangueiro, em Atibaia, SP, em 2008. A metodologia de criação foi baseada em Helle \& Sabelis (1985). Os predadores foram mantidos em uma placa de piso vinílico Paviflex, colocada sobre uma camada de espuma de poliuretano Pro Soft de $4 \mathrm{~cm}$ de espessura, no interior de uma bandeja de plástico ( $35 \mathrm{x}$ $40 \times 8 \mathrm{~cm}$ ). Ao redor da placa de piso, foram dispostas tiras de algodão hidrófilo umedecido que formaram uma arena. Adicionou-se água ao fundo da bandeja, para manter a umidade do algodão e impedir a fuga dos ácaros.

No interior da arena, foram dispostas folhas de feijão-de-porco infestadas com ácaro-rajado, para servir de alimento aos predadores. A bandeja com os ácaros foi mantida em câmara climatizada a $25 \pm 1^{\circ} \mathrm{C}$, UR de $70 \pm 10 \%$ e fotófase de 12 horas.

Os acaricidas sintéticos abamectina, clofentezina, fenpiroximato, fenpropatrina, propargito e enxofre foram testados nas concentrações recomendadas para o controle de T. urticae, em morangueiro, no Brasil (Agrofit, 2009). O espiromesifeno foi testado à concentração de $144 \mathrm{mg} \mathrm{L}^{-1}$ de i.a. Os produtos à base de óleo de nim (A. indica) - Natuneem (Dogneem Produtos Antipragas Naturais, Jaguariúna, SP, Brasil) e Sempre Verde Killer Neem (SVKN) (Bonigo Indústria e Comércio Ltda., Campo Limpo Paulista, SP) foram testados à concentração de $1 \%$ (Tabela 1$)$.

Foram utilizadas as espécies vegetais $D$. brasiliensis (comigo-ninguém-pode), A. squamosa (fruta-do-conde), $R$. graveolens (arruda), A. angustifolia (agave), $M$. azedarach (cinamomo), S. oleraceus (serralha), M. spicata x M. suaveolens (hortelã comum), A. cepa (alho) e L. nobilis (louro). Para o preparo dos extratos aquosos, o material vegetal (bulbos, no caso de alho, e folhas para os demais tratamentos) foi triturado em liquidificador, com água destilada à proporção de $10 \%$ de material vegetal. As coletas do material vegetal e o preparo dos extratos foram realizados em novembro de 2009. Os extratos obtidos foram filtrados 
e armazenados em freezer $\left(-20^{\circ} \mathrm{C}\right)$, pelo período máximo de 60 dias antes da realização dos bioensaios.

Para a condução dos testes toxicológicos, foram preparadas arenas de folha de feijão-de-porco, tendose colocado um disco de folha, com $6 \mathrm{~cm}$ de diâmetro, sobre uma camada de algodão hidrófilo umedecido, em uma placa de Petri de $9 \mathrm{~cm}$ de diâmetro. Foram preparadas quatro placas por tratamento. Para evitar a fuga dos ácaros, a borda da folha foi coberta com algodão umedecido. Em cada arena, foram colocadas 50 fêmeas adultas de T. urticae, com até 48 horas de idade, oriundas da criação estoque, no total de 200 ácaros por tratamento.

A pulverização dos produtos sobre os ácaros foi realizada em torre de Potter (Burkard Scientific, Uxbridge, UK), tendo-se utilizado o volume de calda de $2 \mathrm{~mL}$ e pressão de $0,703 \mathrm{~kg} \mathrm{~cm}^{-2}$, correspondente a um depósito na folha de aproximadamente $1,5 \mathrm{mg} \mathrm{cm}^{-2} \mathrm{de}$ calda. No tratamento testemunha, foi aplicada apenas água destilada. Após a pulverização, as placas foram mantidas em câmaras climatizadas, a $25 \pm 1^{\circ} \mathrm{C}$, UR de $70 \pm 10 \%$ e fotófase de 12 horas.

A mortalidade foi observada 120 horas após a pulverização, com auxílio de um microscópio estereoscópico (40x). Foram considerados mortos os ácaros que não apresentavam movimento, após serem tocados levemente com pincel de pelo macio, conforme indicações de Sato et al. (2007). Utilizou-se o delineamento experimental inteiramente casualizado, com quatro repetições.

O mesmo procedimento experimental foi adotado para $P$. macropilis, porém com um número menor (5) de ácaros por arena, em 40 placas por tratamento. O número total de ácaros por tratamento foi 200.

$\mathrm{O}$ número de tratamentos avaliados para P. macropilis foi menor, pois foram testados apenas os compostos que apresentaram eficiência de controle sobre T. urticae acima de 50\%. Assim, alguns extratos de plantas (cinamomo, arruda, hortelã, fruta-do-conde, comigo-niguém-pode, serralha, eucalipto) não foram utilizados. Os demais tratamentos (alho, agave, louro, óleos de nim, abamectina, clofentezina, fenpropatrina, fenpiroximato, propargito, enxofre e espiromesifeno) foram testados em $P$. macropilis.

As percentagens de mortalidade para as populações de T. urticae e P. macropilis foram corrigidas por meio da fórmula de Abbott (Abbott, 1925) e transformadas para arc sem $(\mathrm{x} / 100)^{0,5}$. As médias de sobrevivência de ácaros para os diferentes tratamentos, em cada espécie, foram comparadas pelo teste de Tukey, a 5\%

Tabela 1. Compostos utilizados para a avaliação da toxicidade e capacidade de reprodução de Tetranychus urticae e Phytoseiulus macropilis.

\begin{tabular}{|c|c|c|c|c|}
\hline Ingrediente ativo & Produto comercial & Formulação & Concentração testada $\left(\mathrm{mg} \mathrm{L}^{-1}\right)$ & Grupo químico \\
\hline Abamectina & Vertimec & $18 \mathrm{EC}$ & 180 & Avermectina \\
\hline Clofentezina & Acaristop & $500 \mathrm{SC}$ & 2.0001 & Tetrazina \\
\hline Fenpropatrina & Danimen & $300 \mathrm{EC}$ & 195 & Piretroide \\
\hline Fenpiroximato & Ortus & $50 \mathrm{SC}$ & 50 & Pirazol \\
\hline Propargito & Acarit & $720 \mathrm{EC}$ & 216 & Sulfito de alquila \\
\hline Enxofre & Kumulus & $800 \mathrm{DF}$ & 4.000 & Inorgânico \\
\hline Espiromesifeno & Oberon & $240 \mathrm{SC}$ & 144 & Derivado do ácido tetrônico \\
\hline Espécie utilizada & Nome comum & Tipo de extrato & Concentração testada $(\%)^{(1)}$ & Família botânica \\
\hline Azadirachta indica & Natuneem & Óleo emulsionado/semente & 1 & Meliaceae \\
\hline Azadirachta indica & Sempre Verde Killer Neem & Óleo emulsionado/semente & 1 & Meliaceae \\
\hline Dieffenbachia brasiliensis & Comigo ninguém pode & Aquoso/folha & 10 & Araceae \\
\hline Annona squamosa & Fruta do conde & Aquoso/folha & 10 & Annonaceae \\
\hline Ruta graveolens & Arruda & Aquoso/folha & 10 & Rutaceae \\
\hline Agave angustifolia & Agave & Aquoso/folha & 10 & Agavaceae \\
\hline Melia azedarach & Cinamomo & Aquoso/folha & 10 & Meliaceae \\
\hline Sonchus oleraceus & Serralha & Aquoso/folha & 10 & Asteraceae \\
\hline Mentha spicata $\mathrm{x}$ M. suaveolens & Hortelã comum & Aquoso/folha & 10 & Lamiaceae \\
\hline Allium сера & Alho & Aquoso/bulbo & 10 & Alliaceae \\
\hline Laurus nobilis & Louro & Aquoso/folha & 10 & Lauraceae \\
\hline Eucalyptus saligna & Eucalipto & Aquoso/folha & 10 & Myrtaceae \\
\hline
\end{tabular}

${ }^{(1)}$ Concentração recomendada em percentagem $\left(\mathrm{v} \mathrm{v}^{-1}\right)$. 
de probabilidade. As comparações entre as espécies (T. urticae e P. macropilis), quanto aos diversos tratamentos, foram realizadas pelo teste t, a $0,1,1$ e $5 \%$ de probabilidade.

Para avaliar o efeito dos tratamentos sobre a taxa de crescimento de $P$. macropilis, 30 fêmeas adultas de T. urticae ( 3 a 5 dias de idade) foram colocadas em uma arena de disco de folha de feijão-de-porco por 24 horas (a $25^{\circ} \mathrm{C}$ ). O número de ovos de T. urticae por arena foi fixado em 150, tendo-se, removido os ovos excedentes. Em seguida, uma fêmea adulta de $P$. macropilis foi colocada na arena infestada com T. urticae. Foram colocados formas ativas e ovos adicionais de T. urticae, em cada arena, à medida que foram consumidos.

No caso de P. macropilis, os compostos utilizados no estudo sobre o efeito no crescimento populacional dessa espécie se limitaram aos extratos de alho e agave, e óleos de nim (duas formulações), em razão da não utilização de produtos de baixa toxicidade a adultos de T. urticae (mortalidade abaixo de 50\%). Os acaricidas sintéticos também foram excluídos desses experimentos por causar a mortalidade quase total dos ácaros $P$. macropilis ou T. urticae (alimento) nas primeiras 120 horas.

As aplicações dos extratos de plantas e óleos de nim, nas suas respectivas concentrações (Tabela 1), foram realizadas em torre de Potter, conforme descrito anteriormente. As arenas com os ácaros foram mantidas a $25 \pm 1^{\circ} \mathrm{C}$, UR de $70 \pm 10 \%$ e 12 horas de fotófase, pelo período de oito dias após o tratamento.

O número total de ácaros $P$. macropilis (ovos, larvas, protoninfas, deutoninfas e adultos) foi contado no oitavo dia após o tratamento. Nesse dia, todas as formas ativas de $P$. macropilis foram contadas e eliminadas das arenas, tendo-se deixado apenas os ovos. Para a avaliação da viabilidade dos ovos, as arenas foram observadas diariamente pelo período adicional de seis dias. Ovos que não deram origem a larvas nesse período foram considerados mortos.

A taxa de crescimento instantâneo $\left(\mathrm{r}_{\mathrm{i}}\right)$ foi calculada pela seguinte equação: $r_{i}=\operatorname{Ln}\left(N_{f} / N_{o}\right) / \Delta t$, em que: $N_{f}$ é o número total de ácaros $P$. macropilis, no oitavo dia após o tratamento; $\mathrm{N}_{\mathrm{o}}$ é o número inicial de ácaros colocados nas arenas no início do bioensaio; e $\Delta$ t é o período em que os ácaros ficaram em contato com o agroquímico (ou duração do experimento) (Stark \& Banks, 2003).
Além dos tratamentos com extratos de planta e óleos de nim, também foi incluída uma testemunha, cuja arena foi pulverizada somente com água destilada. Utilizou-se o delineamento experimental inteiramente casualizado, com 20 repetições.

Para avaliar o efeito dos tratamentos sobre a taxa de crescimento instantâneo de T. urticae, um bioensaio idêntico ao mencionado acima foi conduzido, tendose colocado apenas uma fêmea adulta de T. urticae por arena. $\mathrm{O}$ experimento também contou com 20 repetições por tratamento e foi conduzido por 10 dias. Observações por um período adicional de seis dias também foram realizadas, para avaliação da viabilidade dos ovos de T. urticae. Nos bioensaios de crescimento populacional desse ácaro, não foram incluídos os acaricidas sintéticos.

Dados do número de ovos depositados por fêmea por dia (média durante o período avaliado) e $r_{i}$ foram transformados para $(\mathrm{x}+0,5)^{0,5}$ e submetidos à ANOVA. A comparação entre as médias dos diferentes tratamentos, para cada espécie, foi feita pelo teste de Tukey, a 5\% de probabilidade. A comparação do efeito dos produtos entre as espécies de ácaro foi realizada pelo teste t, a $0,1,1$ e $5 \%$ de probabilidade.

\section{Resultados e Discussão}

Foram observadas diferenças significativas entre os tratamentos quanto à toxicidade sobre $T$. urticae. Os maiores valores de mortalidade (iguais ou superiores a $84 \%$ ) de T. urticae, 120 horas após a aplicação, foram observadosnos tratamentoscompropargito, abamectina, fenpropatrina, espiromesifeno, fenpiroximato, produtos à base de óleo de nim (Natuneem e SVKN), e extratos de alho e de agave. Eficiência intermediária foi observada no extrato de louro, com mortalidade média de $55 \%$. Os demais tratamentos não diferiram significativamente da testemunha (Tabela 2).

Os resultados do presente trabalho corroboram os obtidos com o uso de extratos de agave sobre larvas de mosquito Aedes aegypti (Linnaeus) e Culex quinquefasciatus Say (Pizarro et al., 1999).

Com relação à alta efetividade de extrato de alho para o controle de T. urticae, pouco se conhece sobre os compostos químicos do alho que poderiam explicar os resultados obtidos no presente trabalho. De acordo com Hincapié et al. (2008), compostos como dimetil trissulfeto e dialil dissulfeto podem ser responsáveis 
pelo efeito de repelência aos ácaros, em razão de suas características de volatilidade e forte odor. Vários compostos sulforados, como as vinilditínas, encontrados nessa planta, podem estar relacionados à mortalidade dos ácaros tetraniquídeos.

A mortalidade observada no presente trabalho (máximo de 48\%), causada pelos extratos naturais (eucalipto, serralha, comigo-ninguém-pode, fruta-do-conde, hortelã, cinamomo e arruda), difere da obtida por Potenza et al. (1999a, 2006) e Vieira et al. (2006), com os mesmos extratos, em que, os autores obtiveram mortalidade acima de $70 \%$ para o ácaro-rajado, em condições de laboratório e casa de vegetação.

Uma explicação para essa diferença pode estar relacionada à forma de preparo dos extratos, à espécie da planta (eucalipto) e à concentração utilizada, uma vez que Vieira et al. (2006), utilizaram E. citriodora e concentração dos extratos a $20 \%$. Essa diferença pode estar ainda, associada à influência da época de coleta

Tabela 2. Percentagem de mortalidade ${ }^{(1)}$ de fêmeas adultas de Tetranychus urticae e Phytoseiulus macropilis 120 horas após a pulverização de compostos sintéticos e naturais ${ }^{(2)}$.

\begin{tabular}{|c|c|c|}
\hline Tratamento & T. urticae & P. macropilis \\
\hline Testemunha & $10,62 \pm 0,62 a)$ & $3,00 \pm 3,00 \mathrm{ab}$ \\
\hline Alho & $88,00 \pm 3,46 \mathrm{de}^{* * *}$ & $30,00 \pm 5,77 \mathrm{bcd}$ \\
\hline Agave & $84,00 \pm 8,45 \mathrm{cde}^{* *}$ & $10,00 \pm 5,77 \mathrm{abc}$ \\
\hline Louro & $55,00 \pm 7,14 \mathrm{bcd}$ & $80,00 \pm 11,54 \mathrm{ef}$ \\
\hline Cinamomo & $47,50 \pm 9,54 a b c$ & - \\
\hline Arruda & $48,00 \pm 4,83 \mathrm{abc}$ & - \\
\hline Hortelã & $41,50 \pm 15,17 \mathrm{ab}$ & - \\
\hline Fruta do conde & $34,50 \pm 7,23 \mathrm{ab}$ & - \\
\hline Comigo ninguém pode & $32,50 \pm 12,69 \mathrm{ab}$ & - \\
\hline Serralha & $27,50 \pm 14,57 \mathrm{ab}$ & - \\
\hline Eucalipto & $13,50 \pm 1,50 \mathrm{a}$ & - \\
\hline Natuneem $^{(3)}$ & $95,00 \pm 4,36 \mathrm{e}^{* *}$ & $25,00 \pm 9,57 \mathrm{abcd}$ \\
\hline $\mathrm{SVKN}^{(3)}$ & $93,00 \pm 2,38 \mathrm{de}^{* * *}$ & $45,00 \pm 5,00 \mathrm{cde}$ \\
\hline Enxofre & $23,00 \pm 1,00 \mathrm{ab}^{*}$ & $65,00 \pm 9,57 \mathrm{de}$ \\
\hline Propargito & $100,00 \pm 0,00 \mathrm{e}$ & $100,00 \pm 0,00 \mathrm{f}$ \\
\hline Fenpiroximato & $90,00 \pm 3,65 \mathrm{de}^{*}$ & $100,00 \pm 0,00 \mathrm{f}$ \\
\hline Abamectina & $100,00 \pm 0,00 \mathrm{e}$ & $100,00 \pm 0,00 \mathrm{f}$ \\
\hline Fenpropatrina & $100,00 \pm 0,00 \mathrm{e}$ & $100,00 \pm 0,00 \mathrm{f}$ \\
\hline Espiromesifeno $^{(4)}$ & $98,66 \pm 0,82 \mathrm{e}^{*}$ & $25,00 \pm 16,03 \mathrm{abcd}$ \\
\hline Clofentezina $^{(4)}$ & $43,50 \pm 12,11 \mathrm{ab}$ & $0,00 \pm 0,00 \mathrm{a}$ \\
\hline
\end{tabular}

${ }^{(1)}$ Mortalidade corrigida pela fórmula de Abbott (1925). ${ }^{(2)}$ Médias seguidas de letras iguais, nas colunas, não diferem entre si, pelo teste Tukey, a $5 \%$ de probabilidade. $* * *, * *$ e $*$ Médias na linha diferem entre si, pelo teste $\mathrm{t}$ a $0,1,1$ e $5 \%$ de probabilidade, respectivamente. ${ }^{(3)}$ Produtos à base de óleo de nim Natuneem e Sempre Verde Killer Neem (SVKN). ${ }^{(4)}$ Testes toxicológicos com ovos. Total de 200 ácaros testados por tratamento. do material vegetal na composição química dos óleos essenciais (Morais, 2009).

A mortalidade de $95 \%$ observada no ácaro-rajado quando se utilizou Natuneem, foi superior às obtidas por Brito et al. (2006a, 2006b), que relataram taxas de mortalidade de até $56 \%$ com o uso do mesmo produto e da mesma concentração. Esse contraste pode estar associado às diferenças na metodologia de aplicação. Esses autores utilizaram testes de contato residual; no presente trabalho, no entanto, a aplicação foi feita por pulverização sobre os ácaros, que permaneceram sobre a superfície da folha tratada.

Alta eficiência de produtos como abamectina e espiromesifeno para o controle de T. urticae já havia sido relatada por outros autores (Poletti et al., 2008; Sato et al., 2011). Há, no entanto, relatos de diversas populações resistentes de T. urticae, para as quais abamectina não se mostra eficiente (Sato et al., 2007; Nicastro et al., 2010).

Em relação ao ácaro predador $P$. macropilis, na avaliação de 120 horas, foram observadas percentagens iguais ou inferiores a $45 \%$ de mortalidade causada pelos extratos naturais (alho, agave e produtos à base de óleo de nim) e por clofentezina e espiromesifeno em testes com ovos. Propargito, fenpiroximato, abamectina, fenpropatrina e extrato natural de louro causaram mortalidade entre 80 e $100 \%$.

Taxas de $100 \%$ de mortalidade para P. macropilis também foram observadas por outros autores, para os produtos abamectina (Brito et al., 2006a) e fenpropatrina (Poletti et al., 2008). A taxa de mortalidade (25\%) de $P$. macropilis causada por Natuneem, no presente trabalho, foi maior do que a observada por Brito et al. (2006b), que foi de $11 \%$.

O produto ovicida clofentezina não causou nenhum dano a $P$. macropolis e pode, portanto, ser utilizado para este ácaro. No entanto, o acaricida espiromesifeno causou inviabilidade em $25 \%$ dos ovos de $P$. macropilis e, posteriormente, todas as larvas que eclodiram dos ovos não ultrapassaram o estágio de larva e morreram pela ação do produto químico, o que indica a sensibilidade desse predador a essa molécula química. Embora tenha se mostrado prejudicial a P. macropilis, o acaricida espiromesifeno foi praticamente inócuo ao ácaro predador Neoseiulus californicus (McGregor) (Sato et al., 2011).

$\mathrm{Na}$ comparação do efeito dos compostos sobre as duas espécies de ácaros, os extratos de alho e agave, os 
produtos à base de óleo de nim (Natuneem e SVKN) e clofentezina foram mais prejudiciais a $T$. urticae do que a $P$. macropilis.

Propargito, abamectina e fenpropatrina foram igualmente prejudiciais para ambas as espécies estudadas, com mortalidade de 100\%. O enxofre mostrou-se mais prejudicial a P. macropilis (mortalidade de $65 \%$ ) do que a T. urticae (mortalidade de $23 \%$ ).

A baixa eficiência de enxofre contra $T$. urticae também foi reportada por Sato et al. (2002). Ao contrário do observado em $P$. macropilis, esses autores verificaram que o enxofre era praticamente atóxico ao fitosseídeo N. californicus (Sato et al., 2002).

Foram observados efeitos variados dos diferentes compostos sobre as $r_{i}$ das duas espécies estudadas. Os valores de $r_{i}$ foram positivos para todos os tratamentos, nas duas espécies estudadas, o que indica que nenhum produto levaria à supressão das populações dos ácaros fitófagos ou predadores (Tabela 3 ).

As menores taxas de oviposição e de crescimento instantâneo de T. urticae foram registradas para os produtos à base de nim (Natuneem e SVKN), extratos de alho, agave e louro, com valores iguais ou inferiores a 1,1 ovo por fêmea por dia, e de 0,12 para $r_{i}$. Além dos compostos já mencionados, os extratos de cinamomo e arruda afetaram significativamente a taxa de crescimento de T. urticae. Os demais produtos não diferiram significativamente da testemunha (Tabela 3).
Foram observadas diferenças significativas nas taxas de crescimento de $P$. macropilis em relação à testemunha, quando os ácaros receberam pulverização com extrato natural de alho e com o produto SVKN, que levaram a reduções populacionais de 60 e $69,6 \%$, respectivamente. Os tratamentos com extrato natural de agave e Natuneem foram semelhantes à testemunha e não apresentaram influência significativa na taxa de crescimento populacional de $P$. macropilis. Em relação à taxa de oviposição, somente o tratamento com Natuneem foi semelhante à testemunha.

Comparando-se o efeito dos dois óleos à base de nim (Natuneem e SVNK), observou-se que, apesar de não haver diferenças significativas na taxa de crescimento populacional de T. urticae, verificaram-se contrastes significativos no crescimento populacional de $P$. macropilis, para as diferentes formulações de nim. A taxa de crescimento do ácaro predador foi $50,7 \%$ maior no tratamento com Natuneem do que com SVNK. Essas diferenças entre produtos à base de nim podem estar associadas às variações na composição desses produtos. O teor de azadiractina pode variar de acordo com a parte da planta utilizada para extração e do método de extração. A não padronização no teor de azadiractina em formulações comerciais de nim, no Brasil, pode afetar os programas de manejo integrado de pragas, uma vez que a concentração recomendada pelos fabricantes, geralmente, é a mesma e corresponde a 1\% (Brito et al., 2006a). Contrastes entre formulações

Tabela 3. Número de ovos depositados por fêmea por dia e taxa de crescimento instantâneo ( $\mathrm{r}_{\mathrm{i}}$ ) de Tetranychus urticae e Phytoseiulus macropilis, tratados com extratos naturais e óleos de $\operatorname{nim}^{(1)}$.

\begin{tabular}{|c|c|c|c|c|}
\hline \multirow[t]{2}{*}{ Tratamento } & \multicolumn{2}{|c|}{ № de ovos por fêmea por dia } & \multicolumn{2}{|c|}{$r_{i}$} \\
\hline & T. urticae & P. macropilis & T. urticae & P. macropilis \\
\hline Testemunha & $5,890 \pm 7,089 \mathrm{de}^{* * *}$ & $2,41 \pm 1,398 \mathrm{~d}$ & $0,397 \pm 0,017 \mathrm{e}$ & $0,372 \pm 0,008 \mathrm{c}$ \\
\hline Alho & $0,435 \pm 1,183 a$ & $0,99 \pm 1,341 \mathrm{ab}$ & $0,094 \pm 0,012 \mathrm{ab}$ & $0,269 \pm 0,019 \mathrm{ab}^{* * *}$ \\
\hline Agave & $0,715 \pm 3,842 \mathrm{a}$ & $1,58 \pm 1,291 \mathrm{bc}$ & $0,120 \pm 0,030 \mathrm{ab}$ & $0,324 \pm 0,011 \mathrm{bc} * * *$ \\
\hline Louro & $1,100 \pm 5,850 \mathrm{a}$ & - & $0,100 \pm 0,016 \mathrm{ab}$ & - \\
\hline Cinamomo & $2,510 \pm 4,457 \mathrm{abc}$ & - & $0,263 \pm 0,024 \mathrm{~cd}$ & - \\
\hline Arruda & $1,950 \pm 4,459 \mathrm{ab}$ & - & $0,175 \pm 0,031 b c$ & - \\
\hline Hortelã & $3,720 \pm 6,936 \mathrm{bcd}$ & - & $0,295 \pm 0,032 \mathrm{cde}$ & - \\
\hline Fruta do conde & $5,840 \pm 10,635 \mathrm{de}$ & - & $0,340 \pm 0,041 \mathrm{de}$ & - \\
\hline Comigo ninguém pode & $3,610 \pm 8,039 \mathrm{bcd}$ & - & $0,292 \pm 0,041$ cde & - \\
\hline Serralha & $4,790 \pm 5,189 \mathrm{cde}$ & - & $0,365 \pm 0,020 \mathrm{de}$ & - \\
\hline Eucalipto & $6,865 \pm 6,689 \mathrm{e}$ & - & $0,415 \pm 0,014 \mathrm{e}$ & - \\
\hline Natuneem $^{(2)}$ & $0,650 \pm 0,289 \mathrm{a}$ & $1,92 \pm 1,297 \mathrm{~cd} * * *$ & $0,028 \pm 0,017 \mathrm{a}$ & $0,345 \pm 0,011 \mathrm{c}^{* * *}$ \\
\hline $\mathrm{SVKN}^{(2)}$ & $0,100 \pm 0,149 \mathrm{a}$ & $0,66 \pm 1,229 a^{* *}$ & $0,024 \pm 0,007 \mathrm{a}$ & $0,229 \pm 0,025 \mathrm{a} * * *$ \\
\hline
\end{tabular}

${ }^{(1)}$ Médias seguidas de letras iguais, nas colunas, não diferem entre si, pelo teste Tukey, a $5 \%$ de probabilidade. ***,** e Médias na linha diferem entre si, pelo teste t a $0,1,1$ e $5 \%$ de probabilidade, respectivamente. ${ }^{(2)}$ Produtos à base de óleo de nim Natuneem e Sempre Verde Killer Neem (SVKN). Média de 20 repetições. 
de nim, quanto ao efeito tóxico sobre ácaros predadores (Phytoseiidae) e T. urticae, também foram mencionados por Brito et al. (2006a).

Observa-se, no tratamento testemunha, pela taxa de oviposição das duas espécies, uma capacidade maior de oviposição do T. urticae, que foi $44 \%$ maior que de P. macropilis. No entanto, quando foram utilizados os produtos à base de óleo de nim, o índice de oviposição do predador passou a ser significativamente maior do que o da praga, o que indica maior influência desses compostos sobre a oviposição do T. urticae.

Tanto os extratos de alho e agave, como os produtos à base de óleo de nim, foram mais prejudiciais a T. urticae do que ao predador $P$. macropilis, com diferenças significativas entre as taxas de crescimento, o que indica que o uso desses compostos, em associação com o ácaro predador, pode ser útil em programas de manejo de T. urticae.

O uso desses produtos pode ser vantajoso em áreas (ou períodos) com baixas infestações naturais de predadores dessa espécie ou em cultivos em que a liberação dos predadores se mostrou insuficiente para impedir o crescimento populacional da praga. Nesse caso, os extratos vegetais ou produtos à base de nim podem favorecer o controle da praga e evitar os elevados prejuízos que poderiam ser causados por T. urticae em altas infestações, em culturas como morangueiro e de plantas ornamentais.

Sato et al. (2007) relataram resultados promissores com o uso de ácaros predadores da espécie $N$. californicus, em associação com acaricidas seletivos, como propargito, para o manejo de $T$. urticae em morangueiro. Algumas vantagens do uso de P. macropilis, em associação com extratos de alho ou óleos de nim seriam: maior facilidade de manejo da praga, pois o período de carência é desnecessário para esses produtos (Bernardi et al., 2010); possibilidade de uso de extratos vegetais e nim em cultivos orgânicos; menor risco de intoxicação dos agricultores ou presença de resíduos tóxicos em frutos (Venzon et al., 2008); maior efetividade de $P$. macropilis, em condições de grande infestação de T. urticae (Sato et al., 2007).

\section{Conclusões}

1. Extratos de alho, agave, produtos à base de óleo de $\operatorname{nim}$ (Natuneem e SVKN), espiromesifeno, propargito, fenpiroximato, abamectina e fenpropatrina reduzem a sobrevivência de Tetranychus urticae.

2. Propargito, fenpiroximato, abamectina, fenpropatrina, espiromesifeno e extrato de louro reduzem a população de Phytoseiulus macropilis.

3. Agave e Natuneem não afetam o crescimento populacional do predador $P$. macropilis.

4. Extratos de alho e agave e óleos de nim (Natuneem e SVKN) são mais prejudiciais a T. urticae do que a P. macropilis.

\section{Agradecimentos}

À Fundação de Amparo à Pesquisa do Estado de São Paulo, pelo suporte financeiro; ao Conselho Nacional de Desenvolvimento Científico e Tecnológico, pela concessão de bolsas; ao Dr. Marcos Roberto Potenza, do Instituto Biológico de São Paulo, pelo auxílio na preparação dos extratos vegetais; ao Dr. Jeferson Luiz de Carvalho Mineiro, pela identificação das espécies de ácaro estudadas.

\section{Referências}

ABBOTT, W.S. A method of computing the effectiveness of an insecticide. Journal of Economic Entomology, v.18, p.265-267, 1925.

AGROFIT. Sistema de agrotóxicos fitossanitários, do Ministério da Agricultura, Pecuária e Abastecimento. Disponível em: $<$ http://extranet.agricultura.gov.br/agrofit_cons/principal_agrofit_ cons>. Acesso em: 04 jan. 2009.

BERNARDI, D.; BOTTON, M.; CUNHA, U. da S.; NAVA, D.E.; GARCIA, M.S. Bioecologia, monitoramento e controle do ácaro-rajado com o emprego da azadiractina e ácaros predadores na cultura do morangueiro. Bento Gonçalves: Embrapa Uva e Vinho, 2010. 8p. (Embrapa Uva e Vinho. Circular técnica, 83).

BRITO, H.M.; GONDIM JUNIOR, M.G.C.; OLIVEIRA, J.V. de; CÂMARA, C.A.G. da. Toxicidade de formulações de nim (Azadirachta indica A. Juss.) ao ácaro-rajado e a Euseius alatus De Leon e Phytoseiulus macropilis (Banks) (Acari: Phytoseiidae). Neotropical Entomology, v.35, p.500-505, $2006 \mathrm{a}$.

BRITO, H.M.; GONDIM JÚNIOR, M.G.C.; OLIVEIRA, J.V. de; CÂMARA, C.A.G. da. Toxicidade de Natuneem sobre Tetranychus urticae Koch (Acari: Tetranychidae) e ácaros predadores da família Phytoseiidae. Ciência e Agrotecnologia, v.30, p.685-691, 2006 b.

CHIASSON, H.; BOSTANIAN, N.J.; VINCENT, C. Acaricidal properties of a Chenopodium-based botanical. Journal of Economic Entomology, v.97, p.1373-1377, 2004.

DEVINE, G.J.; BARBER, M.; DENHOLM, I. Incidence and inheritance of resistance to METI-acaricides in European strains 
of the two-spotted spider mite (Tetranychus urticae) (Acari: Tetranychidae). Pest Management Science, v.57, p.443-448, 2001.

FADINI, M.A.M.; VENZON, M.; OLIVEIRA, H.G.; PALLINI, A. Manejo integrado das principais pragas do morangueiro. In: CARVALHO, S.P. de (Coord.). Boletim do morango: cultivo convencional, segurança alimentar, cultivo orgânico. Belo Horizonte: FAEMG, 2006. p.81-95.

GARCIA, I.P.; CHIAVEGATO, L.G. Respostas funcional e reprodutiva de Phytoseiulus macropilis (Banks, 1905) (Acari: Phytoseiidae) a diferentes densidades de ovos de Tetranychus urticae (Koch, 1836) (Acari: Tetranychidae). Científica, v.25, p.35-43, 1997.

HELLE, W.; SABELIS, M.W. Spider mites: their biology, natural enemies and control. Amsterdam: Elsevier, 1985. v.1B, 428p.

HINCAPIÉ, C.A.; LÓPEZ, G.E.; TORRES, R. Comparison and characterization of garlic (Allium sativum L.) bulbs extracts and their effect on mortality and repellency of Tetranychus urticae Koch (Acari: Tetranychidae). Chilean Journal of Agricultural Research, v.68, p.317-327, 2008.

LARCHER, W. Ecofisiologia vegetal. São Carlos: Rima, 2000. 531p.

MARTINEZ, S.S. (Ed.). O nim: Azadirachta indica: natureza, usos múltiplos, produção. Londrina: IAPAR, 2002. 142p.

MORAES, G.J. de; FLECHTMANN, C.H.W. Manual de acarologia: acarologia básica e ácaros de plantas cultivadas no Brasil. Ribeirão Preto: Holos, 2008. 308p.

MORAIS, L.A.S. de. Influência dos fatores abióticos na composição química dos óleos essenciais. Horticultura Brasileira, v.27, p.4050-4063, 2009. Suplemento.

NICASTRO, R.L.; SATO, M.E.; SILVA, M.Z. da. Milbemectin resistance in Tetranychus urticae (Acari: Tetranychidae): selection, stability and cross-resistance to abamectin. Experimental and Applied Acarology, v.50, p.231-241, 2010.

PIZARRO, A.P.B.; OLIVEIRA FILHO, A.M.; PARENTE, J.P.; MELO, M.T.V.; SANTOS, C.E. dos; LIMA, P.R. O aproveitamento do resíduo da indústria do sisal no controle de larvas de mosquito. Revista da Sociedade Brasileira de Medicina Tropical, v.32, p.23-29, 1999.

POLETTI, M.; COLlETTE, L. de P.; OMOTO, C. Compatibilidade de agrotóxicos com os ácaros predadores Neoseiulus californicus (McGregor) e Phytoseiulus macropilis (Banks) (Acari: Phytoseiidae). BioAssay, v.3, p.1-14, 2008.
POTENZA, M.R.; GOMES, R.C.O.; JOCYS, T.; TAKEMATSU, A.P.; RAMOS, A.C.O. Avaliação de produtos naturais para o controle do ácaro rajado Tetranychus urticae (Koch, 1836) (Acari: Tetranychidae) em casa de vegetação. Arquivos do Instituto Biológico, v.73, p.455-459, 2006.

POTENZA, M.R.; TAKEMATSU, A.P.; BENEDICTO, L.H. Avaliação do controle de Tetranychus urticae (Koch, 1836) (Acari: Tetranychidae) através de extratos vegetais, em laboratório. Arquivos do Instituto Biológico, v.66, p.91-97, 1999a.

POTENZA, M.R.; TAKEMATSU, A.P.; SIVIERI, A.P.; SATO, M.E.; PASSEROTTI, C.M. Efeito acaricida de alguns extratos vegetais sobre Tetranychus urticae (koch, 1836) (Acari: Tetranychidae) em laboratório. Arquivos do Instituto Biológico, v.66, p.31-37, 1999b.

SATO, M.E.; SILVA, M. da; GONÇALVES, L.R.; SOUZA FILHO, M.F. de; RAGA, A. Toxicidade diferencial de agroquímicos a Neoseiulus californicus (McGregor) (Acari: Phytoseiidae) e Tetranychus urticae Koch (Acari: Tetranychidae) em morangueiro. Neotropical Entomology, v.31, p.449-456, 2002.

SATO, M.E.; SILVA, M.Z. da; RAGA, A.; CANGANI, K.G.; VERONEZ, B.; NICASTRO, R.L. Spiromesifen toxicity to the spider mite Tetranychus urticae and selectivity to the predator Neoseiulus californicus. Phytoparasitica, v.39, p.437-445, 2011.

SATO, M.E.; SILVA, M.Z. da; SOUZA FILHO, M.F. de; MATIOLI, A.L.; RAGA, A. Management of Tetranychus urticae (Acari: Tetranychidae) in strawberry fields with Neoseiulus californicus (Acari: Phytoseiidae) and acaricides. Experimental and Applied Acarology, v.42, p.107-120, 2007.

SILVA, F.R. da; VASCONCELOS, G.J.N. de; GONDIM JÚNIOR, M.G.C.; OLIVEIRA, J.V. de. Toxicidade de acaricidas para ovos e fêmeas adultas de Euseius alatus Deleon (Acari: Phytoseiidae). Caatinga, v.19, p.294-303, 2006.

STARK, J.D.; BANKS, J.E. Population-level effects of pesticides and other toxicants on arthropods. Annual Review of Entomology, v.48, p.505-519, 2003.

VENZON, M.; ROSADO, M.C.; MOLINA-RUGAMA, A.J.; DUARTE, V.S.; DIAS, R.; PALLINI, A. Acaricidal efficacy of neem against Polyphagotarsonemus latus (Banks) (Acari: Tarsonemidae). Crop Protection, v.27, p.869-872, 2008.

VIEIRA, M.R.; SACRAMENTO, L.V.S.; FURLAN, L.O.; FIGUEIRA, J.C.; ROCHA, A.B.O. Efeito acaricida de extratos vegetais sobre fêmeas de Tetranychus urticae Koch (Acari: Tetranychidae). Revista Brasileira de Plantas Medicinais, v.8, p.210-217, 2006.

Recebido em 30 de maio de 2011 e aprovado em 19 de março de 2012

Pesq. agropec. bras., Brasília, v.47, n.4, p.511-518, abr. 2012 